\title{
BMJ A four-country survey of public attitudes OPen towards restricting healthcare costs by limiting the use of high-cost medical interventions
}

\author{
Robert J Blendon, ${ }^{1}$ John M Benson, ${ }^{1}$ Michael D Botta, ${ }^{2}$ Deborah Zeldow, ${ }^{3}$ \\ Minah Kang Kim ${ }^{4,5}$
}

To cite: Blendon RJ, Benson $\mathrm{JM}$, Botta MD, et al. A four-country survey of public attitudes towards restricting healthcare costs by limiting the use of high-cost medical interventions. BMJ Open 2012; $:$ : 001087

doi:10.1136/

bmjopen-2012-001087

- Prepublication history for this paper is available online. To view this file please visit the journal online (http://dx. doi.org/10.1136/ bmjopen-2012-001087).

Received 9 March 2012 Accepted 4 April 2012

This final article is available for use under the terms of the Creative Commons Attribution Non-Commercial 2.0 Licence; see http://bmjopen.bmj.com

${ }^{1}$ Department of Health Policy and Management, Harvard School of Public Health, Boston, Massachusetts, USA ${ }^{2}$ Program in Health Policy, Harvard University, Cambridge, Massachusetts, USA

${ }^{3}$ Alliance for Aging Research, Washington, DC, USA

${ }^{4}$ Department of Global Health and Population, Harvard School of Public Health, Boston, Massachusetts, USA

${ }^{5}$ Department of Public

Administration, Ewha

Womans University, Seoul,

South Korea

Correspondence to

Dr Professor Robert J

Blendon;

rblendon@hsph.harvard.edu

\section{ABSTRACT}

Objective: To discern how the public in four countries, each with unique health systems and cultures, feels about efforts to restrain healthcare costs by limiting the use of high-cost prescription drugs and medical/ surgical treatments.

Design: Cross-sectional survey.

Setting: Adult populations in Germany, Italy, the UK and the USA.

Participants: 2517 adults in the four countries. A questionnaire survey conducted by telephone (landline and cell) with randomly selected adults in each of the four countries.

Main outcome measures: Support for different rationales for not providing/paying for high-cost prescription drugs/medical or surgical treatments, measured in the aggregate and using four case examples derived from actual decisions. Measures of public attitudes about specific policies involving comparative effectiveness and cost-benefit decision making.

Results: The survey finds support among publics in four countries for decisions that limit the use of highcost prescription drugs/treatments when some other drug/treatment is available that works equally well but costs less. The survey finds little public support, either in individual case examples or when asked in the aggregate, for decisions in which prescription drugs/ treatments are denied on the basis of cost or various definitions of benefits. The main results are based on majorities of the public in each country supporting or opposing each measure.

Conclusions: The survey findings indicate that the public distinguishes in practice between the concepts of comparative effectiveness and cost-effectiveness analysis. This suggests that public authorities engaged in decision-making activities will find much more public support if they are dealing with the first type of decision than with the second.

The rising cost of healthcare is seen as a serious concern in many industrialised countries. Increasingly, the focus by national governments for restraining these costs has been to have independent agencies assess

\section{ARTICLE SUMMARY}

Article focus

- Despite increasing concerns among government officials about high healthcare spending, a survey of the public in four countries finds little support for decisions that limit use of high-cost prescription drugs and treatments.

- The results provide insights for policy-makers, indicating that the public distinguishes in practice between the concepts of comparative effectiveness and cost-benefit analysis. They will generally support decisions related to the first but not the second.

Key messages

- Government agencies dealing with cost-control issues should highlight those decisions not to pay for or provide the more expensive drug or treatment when two prescription drugs or treatments have the same outcome but one is more expensive than the other.

- Policy-makers need to be aware that when they discuss limiting the availability of high-cost prescription drugs or treatments based on the assessment of broader benefits, they may face considerable public controversy.

Strengths and limitations of this study

- This is the only multi-country study of attitudes on this subject. It is unique in that it includes responses for four actual cases where governments made decisions about what should be paid for or provided.

- For general public respondents, these are complex issues that may be difficult to understand, and some responses might differ if respondents were aware of other factors.

whether the benefits of specific high-cost prescription drugs, diagnostic tests and medical or surgical treatments justify their cost. If this is not seen to be the case, these agencies may recommend that payors or government health systems not pay for or provide these medical care interventions. 
In Germany, the Institute for Quality and Efficiency in Healthcare (IQWiG-Institut für Qualität und Wirtschaftlichkeit im Gesundheitswesen) has been responsible for health technology assessments across a range of pharmaceuticals and therapeutics since $2004 .^{1-3}$ In Italy, the Italian Medicines Agency (AIFA-Agenzia Italiana del Farmaco) conducts health technology assessments, evaluating the clinical benefits of new products and, in conjunction with the Pricing and Reimbursement Committee (CPR-Comitato Prezzi e Reimborso), judges cost-effectiveness. ${ }^{4}$ In the UK, the National Health Service has since 1999 relied on the National Institute for Clinical Excellence to generate cost-effectiveness assessments and determine whether new treatments offer enough value to justify adding their costs to the health system. ${ }^{35}$ In the USA, 2010 saw the advent of a new comparative effectiveness agency, the PatientCentered Outcomes Research Institute. However, the new US agency was established with an explicit ban on the use of any cost-effectiveness analysis in payment or provision decisions, in notable contrast to its more empowered European counterparts. ${ }^{6} 7$

As this approach to restraining health costs grows, the question is raised about how accepting the public in these various countries will be to these types of decisions. Healthcare is a visible and popular issue. From one perspective, it might be expected that the public would support these approaches to containing costs and keeping health systems more affordable. On the other hand, they may see these government- or insurancesponsored decisions as interfering in important individual physician and patient choices and thus oppose them.

To date, there has not been an assessment of public attitudes across various countries on this question. A prior survey that looked at part of this overall issue found that the US public was resistant to the use of comparative effectiveness research results for patient care expenditure decisions. The public was supportive of its use for general information, but not decision-making purposes. ${ }^{8}$ An earlier study found that a majority of the German public favoured government not limiting spending for health services, opposed limiting benefits to a core of essential benefits and thought treatment decisions should be made by doctors. ${ }^{9}$ A study in Italy found that when given a single case example, there was considerable public resistance to rationing or priority setting. ${ }^{10}$ In a recent study aimed at examining the German public's attitudes towards proposed criteria for prioritising health services, little evidence of support was found for using age as a criterion. ${ }^{11}$

In this article, we seek to provide an answer about public acceptance of these types of decisions by looking at the findings of a recent four-country survey. The data reported from Germany, Italy, the UK and the USA offer results about public attitudes towards these key questions. It also provides the public response in each country to four case examples of actual decisions in which the high cost of a medical intervention was not thought by payors or governments to be justified by its overall benefits.

\section{METHODS}

The data are derived from a four-country survey by the Harvard School of Public Health and the Alliance for Aging Research. Fieldwork was conducted via telephone (landline and cell) with nationally representative random samples of adults aged 18 years and older in four countries by SSRS/ICR, an independent research company. Interview dates, sample sizes and margins of error are shown below. The sample sizes are typical of public opinion surveys.

\begin{tabular}{llll}
\hline & Interview dates & $\begin{array}{l}\text { Total } \\
\text { interviews }\end{array}$ & $\begin{array}{l}\text { Margin of error } \\
\text { (percentage points) }\end{array}$ \\
\hline Germany & $\begin{array}{l}\text { 30 June 2011 to } \\
\text { 19 July 2011 } \\
\text { 30 June 2011 to } \\
\text { 19 July 2011 }\end{array}$ & 500 & \pm 5.4 \\
Italy & $\begin{array}{l}\text { 30 June 2011 to } \\
\text { 19 July 2011 }\end{array}$ & & \pm 5.4 \\
UK & $\begin{array}{l}\text { 28 June 2011 to } \\
\text { 24 July 2011 }\end{array}$ & \pm 5.4 \\
USA & & \pm 3.9 \\
\hline
\end{tabular}

Non-response in telephone surveys produces some known biases in survey-derived estimates because participation tends to vary for different subgroups of the population. To compensate for these known biases, a poststratification weighting design was used to weight all collected interviews to represent each country's adult population. Weighting targets included telephone status (landline, cell) and various individual demographics: race/ethnicity (USA only), age, gender, education and region. Other techniques, such as callbacks staggered over times of days and days of weeks and systematic respondent selection within households, are used to help ensure that the sample in each country is representative.

After weighting, the sample for each country reflects the demographic composition of the adult population of that country. The results for each country are generalisable to the adult population of that country.

The survey instrument comprised a range of questions relating to support for different rationales for not providing/paying for high-cost prescription drugs/ medical or surgical treatments, measured in the aggregate and using four-case examples derived from actual decisions and attitudes about specific policies involving comparative effectiveness and cost-benefit decision making. The question wordings are shown in more detail on the three tables.

The survey included four case examples, derived from comparative effectiveness decisions that had actually been made in one or another of the countries. Respondents were read a paragraph about the decision, 
without mention of the country where the decision was made or the name of the prescription drug or diagnostic test involved and then asked whether they approved or disapproved of the decision. The content of the case examples, whose wordings appear in table 2, were derived from journal or newspaper accounts or the actual decision. The drug/test, disease and country for the four decisions were (1) Avastin/bowel cancer/UK, ${ }^{12}$ (2) Avastin/Lucentis/wet age-related macular degeneration (wet AMD) $/$ Italy, ${ }^{13}$ (3) $\beta$ interferon/multiple sclerosis $/ \mathrm{UK}^{14}$ and (4) positron emission tomography (PET scans)/head and neck tumours/Germany. ${ }^{15}$

Many of the questions in the survey were asked of split samples, where one half was asked about prescription drugs and the other half about medical or surgical treatments. Because the responses of the two half samples were similar, the data for the two forms were combined for clarity of presentation and to increase statistical power. In the UK and Italy, questions were asked about 'the national health service providing...' In Germany and the USA, questions were asked about 'the government or health insurance plans paying for...'

Data analysis comprises descriptive statistics to ascertain public attitudes on each of the measures. Percentages and CIs (at the 95\% confidence level) are shown for the responses to each survey item in each country. The base for calculating percentages included all respondents who were asked the question, so there are no missing data. 'Don't know/refused' responses are included in the base but are not shown in the tables unless they are $10 \%$ or greater for the question in one or more countries.

The Institutional Review Board at the Harvard School of Public Health ruled that this study is not human

Table 1 Public attitudes in four countries about comparative effectiveness decision making and patient access (in per cent)

\begin{tabular}{llll} 
Germany $(n=500)$, & Italy $(n=500)$, & UK $(n=500)$, & USA $(n=1017)$, \\
$\%(95 \% \mathrm{Cl})$ & $\%(95 \% \mathrm{Cl})$ & $\%(95 \% \mathrm{Cl})$ & $\%(95 \% \mathrm{Cl})$ \\
\hline
\end{tabular}

In (your country) the (government or health insurance plans withhold/national health service withholds) high-cost (prescription drugs/medical or surgical treatments) from people who might benefit in order to save money...

$\begin{array}{lllll}\text { Very often } & 15(11 \text { to } 19) & 19(15 \text { to } 24) & 11(7 \text { to } 14) & 29(26 \text { to } 33) \\ \text { Somewhat often } & 43(38 \text { to } 48) & 36(31 \text { to } 41) & 28(23 \text { to } 33) & 38(34 \text { to } 41) \\ \text { Not too often } & 30(25 \text { to } 35) & 25(20 \text { to } 29) & 39(33 \text { to } 44) & 20(17 \text { to } 23) \\ \text { Not at all } & 4(2 \text { to } 7) & 9(6 \text { to } 12) & 19(15 \text { to } 23) & 7(5 \text { to } 9) \\ \text { Don't know/refused } & 7(4 \text { to } 10) & 11(8 \text { to } 14) & 4(1 \text { to } 6) & 6(4 \text { to } 8)\end{array}$

Paying for/providing approved (prescription drugs/medical or surgical treatments) regardless of cost (respondents were asked to choose between two statements:)

The (government or health insurance 61 (56 to 66$) \quad 77$ (72 to 81) 60 (55 to 65) 59 (55 to 62)

plans should pay for/national health

service should provide) any

(prescription drug/medical or surgical

treatment) that has been approved

as being safe and effective for saving

lives or improving people's health,

regardless of what it costs

There are so many new expensive

prescription drugs and medical or

35 (29 to 40$)$

20 (16 to 24$)$

38 (33 to 43$)$

35 (31 to 39$)$

surgical treatments that it is too

expensive for (government or health

insurance plans to pay for/the

national health service to provide) all

of them

The (government or your health insurance plan paying for/national health service providing) more expensive (prescription drug/ medical or surgical treatment) recommended by your doctor even if it has not been shown to work better than less expensive (drugs/treatments)

Favour paying for/providing (oppose

comparative effectiveness)

Oppose paying for/providing (favour

comparative effectiveness)

43 (37 to 48 )

49 (44 to 54$)$

21 (17 to 25$)$

29 (24 to 34$)$

33 (29 to 37 )

Some (prescription drugs/medical or surgical treatments) that have been shown to be safe and effective should not be (paid for by the government or health insurance plans/provided by the national health service) because their high cost is not felt to be justified by the amount of benefit they provide
Favour not paying for/providing
32 (27 to 37$)$
31 (26 to 36$)$
34 (28 to 39$)$
31 (27 to 34$)$
Oppose not paying for/providing
59 (54 to 65)
61 (56 to 66$)$
$63(58$ to 68$)$
$62(59$ to 66$)$

Source: Harvard School of Public Health/Alliance for Aging Research Survey, 2011.

'Don't know/refused' responses not shown unless they are $10 \%$ or greater for the question in one or more countries. 
subjects research (Protocol \#20104-101, 16 December 2010).

\section{RESULTS}

Across the four countries, many people believe that highcost drugs and treatments are already often being withheld. Majorities of the public in Germany (58\%), Italy $(55 \%)$ and the USA $(67 \%)$ believe that in their country, high-cost prescription drugs/medical or surgical treatments are very or somewhat often withheld from some people who might benefit from them in order to save money. This belief is not shared by a majority in the UK, where $39 \%$ believe drugs/treatments are often withheld (table 1).

Majorities in all four countries believe that any prescription drug/medical or surgical treatment that has been approved as safe and effective for saving lives or improving people's health should be paid for or provided, regardless of cost. Paying for or providing these drugs/treatments is favoured by about threefourths of the public in Italy $(77 \%)$ and about six in 10 in Germany $(61 \%)$, the UK $(60 \%)$ and the USA $(59 \%)$.

A majority in Italy $(70 \%)$, the UK $(69 \%)$ and the USA $(64 \%)$ oppose the government, health insurance plans or the national health service paying for or providing a prescription drug/medical or surgical treatment recommended by their doctor if it has not been shown to work better than less expensive ones. This view is shared by a plurality (49\%) in Germany. This is often referred to as comparative effectiveness research.

However, the public does not support decisions in which prescription drugs/medical or surgical treatments are denied on the basis of cost or various definitions of benefits. The public was asked whether some prescription drugs/medical or surgical treatments that have been shown to be safe and effective should not be paid for or provided because of their high cost is not felt to be justified by the amount of benefit they provide. About six

Table 2 Public attitudes in four countries about actual coverage decisions (in per cent)

\begin{tabular}{llll}
$\begin{array}{l}\text { Germany }(n=250), \\
\%(95 \% \mathrm{Cl})\end{array}$ & $\begin{array}{l}\text { Italy }(n=250), \\
\%(95 \% \mathrm{Cl})\end{array}$ & $\begin{array}{l}\text { UK }(n=250), \\
\%(95 \% \mathrm{Cl})\end{array}$ & $\begin{array}{l}\text { USA }(n=509), \\
\%(95 \% \mathrm{Cl})\end{array}$ \\
\hline
\end{tabular}

In one country, the national government decided against (paying for/providing) a new drug for treating an advanced form of cancer. On average, the drug costs $(\$ 35000 / £ 21000 / € 25000)$ per patient. The drug does not cure the disease, but studies suggest that using the drug can add, on average, about 6 months to a patient's life. Some patients would gain only a short period, while others could gain a lot more time. If this decision not to (pay for/provide) this drug were made in (your country), would you approve or disapprove of the decision?
Approve
36 (28 to 43)
39 (32 to 47)
24 (17 to 30 )
37 (32 to 43)
Disapprove
60 (53 to 68)
51 (44 to 59)
76 (69 to 82)
59 (54 to 65)

In one country, two drugs were available to treat a debilitating condition in the elderly. One of the drugs costs about 100 times as much as the other. The more expensive one has been tested and shown to be effective for people with this condition. The less expensive one has not been tested in research studies for treating this illness. However, many physicians who specialise in the condition use the lower cost drug because they believe it is safe and effective for their patients. This is often referred to as using an off-label drug. The government in that country decided to pay for/provide/pay only the less expensive drug even though it had not been tested for this illness. If this decision only to (pay for/provide) the less expensive drug that had not been tested for this illness were made in (your country), would you approve or disapprove of the decision?
Approve
24 (18 to 31$)$
25 (18 to 31$)$
20 (14 to 26$)$
26 (21 to 31$)$
Disapprove
70 (63 to 78 )
$71(64$ to 80$)$
80 (74 to 86$)$
$71(66$ to 76$)$

A new drug is available for a serious debilitating disease. It does not cure the disease, but it can provide relief for the symptoms of the disease. In one country, the national government decided to (pay for/provide) this drug only for a limited number of patients because of the drug's high cost of $(\$ 15000 / £ 9000 / € 11000)$ a year. The drug is reserved for those patients who are most likely to see significant health benefits. Some people have objected to the decision because they argue that other patients might also benefit from the drug. If this decision to (pay for/provide) this drug only for a limited number of patients were made in (your country), would you approve or disapprove of the decision?
Approve
28 (21 to 35$)$
26 (20 to 32$)$
$27(20$ to 34$)$
$28(22$ to 33$)$
Disapprove
66 (58 to 73 )
71 (64 to 77$)$
72 (65 to 79$)$
$69(64$ to 75$)$

In one country, the national government decided against (paying for/providing) the use of an imaging technology for diagnosing certain types of cancers. The technology is more expensive than alternative methods, costing over $(\$ 2000 / £ 1200 / € 1400)$ per use. After conducting an evaluation, a government organisation concluded that there was not enough scientific evidence to recommend using the technology for these other types of cancer. Other countries, however, actively use this technology for multiple types of cancer because many doctors believe it provides the best most detailed view of these other types of tumours. The evaluation organisation argued that existing studies have not conclusively proven that the technology has advantages over alternative methods and therefore should not be (paid for/provided). If this decision not to (pay for/provide) this technology to help diagnose these other types of cancer were made in (your country), would you approve or disapprove of the decision?
Approve
26 (19 to 32$)$
$53(46$ to 60$)$
18 (13 to 24$)$
34 (28 to 39)
Disapprove
67 (60 to 75)
39 (32 to 47)
78 (71 to 84 )
63 (57 to 68)

Source: Harvard School of Public Health/Alliance for Aging Research Survey, 2011.

'Don't know/refused' responses not shown. 
Table 3 Public attitudes in four countries about government decision-making about costs of medical interventions (in per cent)

\begin{tabular}{llll} 
Germany $(n=500)$, & Italy $(n=500)$, & UK $(n=500)$, & USA $(n=1017)$ \\
$\%(95 \% \mathrm{Cl})$ & $\%(95 \% \mathrm{Cl})$ & $\%(95 \% \mathrm{Cl})$ & $\%(95 \% \mathrm{Cl})$ \\
\hline
\end{tabular}

Favour/oppose (your country) having a government decision-making body that recommends whether government programmes should pay for/provide (prescription drugs/medical or surgical treatments) if they think they cost too much
Favour
71 (66 to 76$)$
69 (64 to 74$)$
46 (40 to 51$)$
43 (39 to 47$)$
Oppose
21 (17 to 25$)$
23 (18 to 27 )
48 (42 to 53 )
54 (50 to 58$)$

Such a government decision-making body would provide doctors with useful scientific information about what works best for patients with a given disease or medical condition

$\begin{array}{lllll}\text { Yes } & 64(59 \text { to } 69) & 87(84 \text { to } 90) & 67(62 \text { to } 73) & 55(51 \text { to } 59) \\ \text { No } & 27(22 \text { to } 31) & 7(5 \text { to } 9) & 27(23 \text { to } 32) & 40(36 \text { to } 43)\end{array}$

Trust the national government to make the right healthcare decisions

$\begin{array}{lllll}\text { Trust } & 42(37 \text { to } 47) & 54(49 \text { to } 59) & 54(49 \text { to } 59) & 34(30 \text { to } 38) \\ \text { Do not trust } & 53(48 \text { to } 58) & 35(30 \text { to } 40) & 39(34 \text { to } 44) & 61(57 \text { to } 65) \\ \text { Don't know/refused } & 5(3 \text { to } 7) & 11(8 \text { to } 14) & 7(4 \text { to } 10) & 4(3 \text { to } 5)\end{array}$

Source: Harvard School of Public Health/Alliance for Aging Research Survey, 2011.

'Don't know/refused' responses not shown unless they are $10 \%$ or greater for the question in one or more countries.

in $10-59 \%$ in Germany, $61 \%$ in Italy, $63 \%$ in the UK and $62 \%$ in the USA-were opposed.

When it comes to case examples of specific decisions involving cost and benefits that have been made, majorities in all four countries disapproved of three of the four decisions presented in the survey. In a fourth case example, a decision not to pay for or provide an imaging technology for diagnosing certain types of cancer, majorities in three of the countries disapproved, while a majority in Italy approved (table 2).

The survey asked people whether they would favour or oppose their country having a government decisionmaking body that recommends whether government programmes should pay for or provide prescription drugs/medical or surgical treatments if they think they cost too much. Public opinion in the four countries differs. Majorities in Germany $(69 \%)$ and Italy $(71 \%)$ favour having such an agency. A majority $(54 \%)$ in the USA oppose having such an agency, while $43 \%$ favour having one. The public in the UK is about evenly divided, with $46 \%$ in favour and $48 \%$ opposed (table 3 ).

In spite of these differences in approval for a government decision-making body, majorities in all four countries believe that such an agency would provide doctors with useful scientific information about what works for patients with a given disease or medical condition.

With regard to governmental decision-making in healthcare, majorities in Italy and the UK say that they trust their national government to make the right healthcare decisions, while majorities in Germany and the USA say they do not.

\section{DISCUSSION}

The survey findings indicate that the public distinguishes in practice between the concepts of comparative effectiveness and cost-benefit analysis. When two prescription drugs or treatments have the same outcome but one is more expensive than the other, the public supports policies that would not pay for or provide the more expensive one in the absence of evidence that it would work better than the less expensive alternative.

On the other hand, the survey found little public support, either in individual case examples or when asked in the aggregate, for the establishment of broader benefits as a criterion for whether or not a drug or treatment should be paid for or provided. If the evidence shows that a drug or treatment benefits some patients for some period of time, the public is reluctant to have these medical interventions not paid for or provided.

Taken together, this suggests that across the four countries, public authorities engaged in decision-making activities will find much more public support if they are dealing with the first type of decision than with the second. In addition, public officials may face public resistance for decision-making about whether to pay for or provide high-cost medical interventions because a large proportion of the public believes that some highcost prescription drugs and treatments are already being withheld.

This study has two main limitations. First, these types of policy-making decisions may be difficult for the general public to understand fully. Second, although respondents were told that these types of decisions were being made as a way of limiting future healthcare costs, they might have answered differently had they been told that these decisions might lower their taxes or health insurance premiums in the future, if that were the case.

Contributors RJB and JMB made substantial contributions to the conception and design of the study, as well as the analysis and interpretation of the data and drafted the article. MDB and MKK made substantial contributions to the conception and design of the study, the analysis and interpretation of the data and the critical revision of the article. DZ made substantial contributions to the conception and design of the study and to the critical revision of the article. All authors gave final approval of this version of the article. No one who fulfils the criteria for authorship has been excluded as an author.

Funding The survey was supported by a grant to the Alliance for Aging Research from Bayer AG. Bayer was not involved in the design of the survey, the data collection, the analysis or the interpretation of findings or the 
preparation of the manuscript. The authors had full access to all data in the study and had full responsibility for the decision to submit for publication.

Competing interests All authors have completed the Unified Competing Interest form at http://www.icmje.org/coi_disclosure.pdf (available on request from the corresponding author). RJB, JMB, MDB and MKK acted as subcontractors under an Alliance for Aging Research grant. DZ declares that the organisation by which she is employed, the Alliance for Aging Research, received a grant from Bayer $A G$ for this survey.

Provenance and peer review Not commissioned; externally peer reviewed.

Data sharing statement The topline results of the survey are publicly available at http://www.hsph.harvard.edu/news/press-releases/files/blendon_topline_ aging_12.11.pdf. Within 6 months, the data set will be made available at a public opinion data archive.

\section{REFERENCES}

1. European Observatory on Health Care Systems. Health Care Systems in Transition: Germany. 2000. http://www.euro.who.int/ data/assets/ pdf_file/0010/80776/E68952.pdf (accessed 30 Mar 2012).

2. Jonsson B. IQWiG: an opportunity lost? Eur J Health Econ 2008;9:205-7.

3. Chalkidou K, Tunis S, Lopert R, et al. Comparative effectiveness research and evidence-based health policy: experience from four countries. Millbank Q 2009;87:339-67.

4. France $\mathrm{G}$, Taroni F, Donatini $\mathrm{A}$. The Italian health-care system. Health Econ 2005;14(Suppl 1):S187-202.

5. Macarthur D. Pharmaceutical pricing and reimbursement in the United Kingdom. Health Economics in Prevention and Care 2000;1:47-50.
6. Kamerow D. PCORI: odd name, important job, potential trouble. BMJ 2011;342:d2635

7. Iglehart JK. The political fight over comparative effectiveness research. Health Aff (Millwood) 2010;29:1757-60.

8. Gerber AS, Patashnik EM, Doherty D, et al. The public wants information, not board mandates, from comparative effectiveness research. Health Aff (Millwood) 2010;29: 1872-81.

9. Busse R. Priority-setting and rationing in German health care. Health Policy 1999;50:71-90.

10. Fattore G. Clarifying the scope of Italian NHS coverage. Is it feasible? Is it desirable? Health Policy 1999;50:123-42.

11. Diederich A, Winkelhage J, Wirsik N. Age as a criterion for setting priorities in health care? A survey of the German public view. PLoS One 2011;6:e23930. http://www.plosone.org/article/info\%3Adoi \%2F10.1371\%2Fjournal.pone.0023930 (accessed 30 Mar 2012).

12. Smith R. Bowel cancer drug Avastin turned down by NICE. The Telegram 24 August 2010. http://www.telegraph.co.uk/health/ healthnews/7959762/Bowel-cancer-drug-Avastin-turned-down-byNice.html (accessed 30 Mar 2012).

13. Pavlou F. Avastin to be reimbursed by Italian authorities. Ophthalmology Times Europe 1 July 2007. http://www.oteurope.com/ ophthalmologytimeseurope/content/printContentPopup.jsp? id=476054 (accessed 30 Mar 2012).

14. Kernick D. Beta interferon, NICE, and rationing. $\mathrm{Br} J$ Gen Pract 2002;52:784-5.

15. Institute for Quality and Efficiency in Health Care. Benefit of Positron Emission Tomography (PET) in Patients with Head and Neck Tumors cannot be Assessed. 2011. https://www.iqwig.de/benefit-ofpositron-emission-tomography-pet-in.1287.en.html (accessed 30 Mar 2012). 